\title{
Simultaneous observations of Polar Mesosphere Summer Echoes at two different latitudes in Antarctica
}

\author{
H. Nilsson ${ }^{1}$, S. Kirkwood ${ }^{1}$, R. J. Morris ${ }^{2}$, R. Latteck ${ }^{3}$, A. R. Klekociuk ${ }^{2}$, D. J. Murphy ${ }^{2}$, M. Zecha ${ }^{3}$, and E. Belova ${ }^{1}$ \\ ${ }^{1}$ Swedish Institute of Space Physics, Kiruna, Sweden \\ ${ }^{2}$ Australian Antarctic Division, Kingston, Tasmania, Australia \\ ${ }^{3}$ Leibniz-Institute of Atmospheric Physics, Kühlungsborn, Germany
}

Received: 28 April 2008 - Revised: 21 October 2008 - Accepted: 22 October 2008 - Published: 27 November 2008

\begin{abstract}
Simultaneous observations of Polar Mesosphere Summer Echoes (PMSE) at Wasa and Davis in Antarctica have been compared. Data with simultaneous observations were obtained for 16 days between 18 January and 5 February 2007. Wasa is at a higher geographic latitude than Davis, but at lower geomagnetic latitude. PMSE strength and occurrence frequency were significantly higher at Wasa. The variation of daily PMSE occurrence over the measurement period was in agreement with temperature and frost-point estimates from the Microwave Limb Sounder on the Aura spacecraft for both Wasa and Davis. The diurnal variation of PMSE strength and occurrence frequency as well as the shape of the altitude profiles of average PMSE strength and occurrence frequency were similar for the two sites. The deepest part of the evening minimum in PMSE occurrence frequency occurred for the same magnetic local time at the two sites rather than for the same local solar time. The study indicates that PMSE strength and occurrence increase between $68.6^{\circ}$ and $73^{\circ}$ geographic latitude, consistent with observed differences in mesospheric temperatures and water vapor content. The average altitude distribution of PMSE varies relatively little with latitude in the same hemisphere.
\end{abstract}

Keywords. Atmospheric composition and structure (Aerosols and particles; Middle atmosphere - composition and chemistry) - Meteorology and atmospheric dynamics (Middle atmosphere dynamics)

\section{Introduction}

Polar Mesosphere Summer Echoes (PMSE) are radar echoes from the summer mesopause. PMSE results from electron density inhomogeneities at the radar Bragg scale, mainly caused by charged subvisual aerosols. Layered atmospheric

Correspondence to: H. Nilsson

(hans.nilsson@irf.se) turbulence appears to play a role as well. The aerosols may grow to visual size to cause the related phenomena of polar mesospheric clouds. PMSE requires temperature below the frost point and an ionization source: solar Lyman $\alpha$ or energetic charged particle precipitation. For a recent review of the formation mechanism behind PMSE see Rapp and Lübken (2004).

As more VHF radars have become available for the study of PMSE, it has become possible to investigate latitudinal and hemispheric differences in the strength and occurrence frequency of these strong radar echoes. The reports regarding latitude dependence are somewhat contradictory: Lübken et al. (2004b) found PMSE to be more prevalent at higher latitudes in the European sector, whereas Huaman et al. (2001) found PMSE to be less prevalent at higher latitude. Initial measurements of PMSE in the Southern Hemisphere failed to detect any PMSE at $62^{\circ} \mathrm{S}$ latitude (Balsley et al., 1993), and later measurements from the same site showed only weak PMSE (Woodman et al., 1999). This could be interpreted as a large temperature difference of $7.5 \mathrm{~K}$ between the two hemispheres. Sounding rocket measurements of the temperature at $68^{\circ}$ did not find such a large temperature difference between the hemispheres (Lübken et al., 2004a). Later PMSE measurements has also been made from Davis, Antarctica, (Morris et al., 2006, 2007) and Wasa, Antarctica (Kirkwood et al., 2007). Direct latitude comparisons have so far only been reported for the Northern Hemisphere.

The different radars used to study PMSE have varying characteristics. Comparison of the underlying physical process requires a proper inter-calibration of the different radars being used. To date only four such inter-calibrated comparisons have been published: Two hemispherical comparisons between Andenes in northern Scandinavia and Davis in Antarctica (Latteck et al., 2007; Morris et al., 2008), a hemispherical comparison between Kiruna in northern Scandinavia and Wasa in Antarctica (Kirkwood et al., 2007) and finally a study involving Andenes and Resolute Bay in

Published by Copernicus Publications on behalf of the European Geosciences Union. 
Table 1. Summary of radar parameters.

\begin{tabular}{lll}
\hline Radar site & Wasa & Davis \\
\hline Frequency & $54.5 \mathrm{MHz}$ & $55 \mathrm{MHz}$ \\
Peak power & $20 \mathrm{~kW}$ & $49.3 \mathrm{~kW}$ \\
Antenna Gain & $23.6 \mathrm{dBi}$ & $28.9(21.0) \mathrm{dBi}$ \\
Tx beam width fwhm & $12^{\circ}$ & $6^{\circ}$ \\
System efficiency & 0.75 & 0.5 \\
Radar pulse length & $495 \mathrm{~m}$ & 450 \\
Geographic coord. & $73.04^{\circ} \mathrm{S}, 13.41^{\circ} \mathrm{W}$ & $68.6^{\circ} \mathrm{S}, 78.0^{\circ} \mathrm{E}$ \\
Geomag. lat. & $61.3^{\circ} \mathrm{S}$ & $74.4^{\circ} \mathrm{S}$ \\
Magn. midnight & $01: 18 \mathrm{LST}$ & $03: 23 \mathrm{LST}$ \\
\hline
\end{tabular}

the Northern Hemisphere and Davis in the Southern Hemisphere (Latteck et al., 2008). What these studies found was that for comparable geographical latitudes (Andenes $\left(69.3^{\circ} \mathrm{N}\right)$ and Davis $\left(68.6^{\circ} \mathrm{S}\right)$ the PMSE occurrence frequency and strength were significantly lower in the Southern Hemisphere. When comparing PMSE between Kiruna $\left(67.9^{\circ} \mathrm{N}\right)$, and Wasa Antarctica, at a higher geographical latitude $\left(73.0^{\circ} \mathrm{S}\right)$, the PMSE strength and occurrence frequency were similar. Finally the PMSE strength and occurrence frequency at Resolute Bay $\left(75^{\circ} \mathrm{N}\right)$ were much less than at the lower latitude Andenes site.

Interhemispheric and latitude differences have been modelled by Lübken and Berger (2007) using the LIMA/ice model. Their model reproduces the interhemispheric difference in PMSE strength and occurrence between Andenes and Davis (Latteck et al., 2007). They also find that the differences between the hemispheres are smaller at higher latitudes and that generally PMSE should be more prevalent and the PMSE season longer at higher latitudes. The latitude dependence of the model is however at odds with the Resolute Bay results (Latteck et al., 2008; Huaman et al., 2001). Clearly it is worthwhile to further compare simultaneous PMSE data from different latitudes and compare this with the LIMA/ice model.

In this paper we compare simultaneous calibrated measurements from Davis at $69^{\circ} \mathrm{S}$ and Wasa at $73^{\circ} \mathrm{S}$ geographic latitude. These two sites are also at very different geomagnetic latitudes: $74.4^{\circ}$ for Davis vs. $61.3^{\circ}$ for Wasa.

\section{Observational technique}

We use data from the Movable Atmospheric Radar for Antarctica (MARA) and the MST radar at Davis. The MARA radar is described in Kirkwood et al. (2007). The Davis radar is described in Morris et al. (2006) and Latteck et al. (2007). Some of the characteristics are given in Table 1. Radar pulse length is given for the radar mode used in this study. In order to compare calibrated values, we calculate the volume radar reflectivity for both radars (Gage, 1990). The volume radar reflectivity is given by

$\eta=\frac{P_{r}}{P_{t}} \frac{256(2 \ln 2) r^{2}}{\pi e G_{r} \lambda^{2} \Delta r F}$

where $P_{r}$ is the received power, $P_{t}$ is the transmitted power, $r$ is the distance to the scattering volume, $\Delta r$ is the pulse length in meters, $e$ is the efficiency factor given in Table 1 , $G_{r}$ is the antenna receiver gain and $F$ is the volume fill factor. The formula is valid for the case when the whole scattering volume defined by the transmitter antenna contribute to the scatter, and is within the volume received by the receiver antenna. For the MARA radar at Wasa the receiver antenna is the same as the transmitter antenna. For Davis, only one antenna group has been used in the estimate of the received signal strength, so the receiver antenna gain is about $1 / 6$ of the transmitter gain (value in brackets in Table 1). We have assumed a fill factor of 1 in our calculations; i.e. that is we have isotropic volume scatter and that transmitter beam width is less than or equal to the beam width on reception. The latter condition is satisfied by the experimental configuration. The former condition may not be satisfied. For the purpose of comparison between the radars the most important factor is that the scatter may be stronger from close to zenith than in the rest of the scattering volume. For exactly the same PMSE this would lead to a higher volume reflectivity estimate from the Davis radar than the Wasa radar due to the concentration of the transmitter beam closer to zenith for Davis.

We have also used temperature and water vapor estimates from the Microwave Limb Sounder (MLS) on the Aura spacecraft. The temperature and geopotential height estimates from MLS processing software V2.2 are discussed in detail by Schwartz et al. (2008), and the MLS middle atmosphere water vapor data are discussed in Lambert et al. (2007). We used data gridded with $3 \mathrm{~km}$ resolution in geopotential height. Such a comparison between Aura MLS data and Davis radar data has previously been reported by Morris et al. (2007), for the PMSE season 2004/2005. We also use wind estimates from the medium frequency (MF) radar at Davis (Murphy et al., 2007) in order to compare the presence of PMSE with zonal and meridional winds.

\section{Results}

\subsection{Day-to-day variation of PMSE strength and occurrence}

For the occurrence frequency study we have used a detection threshold at a volume reflectivity of $10^{-15} \mathrm{~m}^{-1}$. The threshold was chosen so as to be well above the background noise at Wasa, see Kirkwood et al. (2007) for details. The more powerful Davis radar can detect weaker PMSE than this, this is one reason why it is important to compare volume reflectivity and occurrence above a specified volume reflectivity threshold when comparing data from different radars. Figure 1 
shows the relative occurrence of PMSE above this threshold for each day with observations. Wasa data are shown in the upper panel, and Davis data in the lower panel. The occurrence frequency is calculated over all altitude gates and sampling times in the 80 to $90 \mathrm{~km}$ altitude region. Therefore PMSE above the threshold in half the altitude gates all the time would yield an occurrence frequency of $50 \%$. Occurrence shown is for the time the radar was running on each day, which is always $24 \mathrm{~h}$ for Davis. For Wasa this is on some occasions only a fraction of the day. Days without measurements at Wasa or with significant data gaps are indicated with horizontal red bars in Fig. 1. Some other days contain smaller data gaps of about $1 \mathrm{~h}$. If the occurrence frequency for Davis is calculated only for time periods when we have data from the Wasa radar the occurrence frequency at Davis is somewhat lower. The data gaps and the distribution of the PMSE is shown with $15 \mathrm{~min}$ time resolution in Fig. 2. The y-axis of Fig. 2 shows the date, and the y-axis shows the local solar time. Occurrence frequency is colour coded according to the bar to the right of the main panels, and were calculated for the altitude range 80 to $90 \mathrm{~km}$. White in panel (a) (Wasa) indicates data gaps. There are no data gaps in the Davis data.

PMSE above a volume reflectivity of $10^{-15} \mathrm{~m}^{-1}$ is more common above Wasa. A marked minimum in PMSE occurrence can be seen; from 23 January to 26 January at Davis, around the time of a minimum at Wasa on 25 January. Both radars show peaks in the PMSE occurrence rates in the beginning of the measurement period (18-20 January for Davis) and in the period 31 January to 1 February (Davis) and 30 January to 3 February (Wasa). There is no clear evidence that these variations are due to planetary waves. For example the 5 day planetary wave which is well known to modulate PMSE and noctilucent clouds in the Northern Hemisphere (Kirkwood et al., 2002; Kirkwood and Stebel, 2003) would have a 5 day cycle and more than 1 day phase shift between Wasa and Davis. Some variability with approximately a 5 day period can be discerned in the Davis data, but the closest corresponding peaks/troughs at Wasa have a rather variable phase relation. There is no evident 5 day wave modulation in the Wasa data.

Davis MF radar winds show strong positive (equatorward) meridional wind around the time of the first maximum in PMSE occurrence frequency and generally positive meridional wind during the second maximum as shown in Fig. 3, panel (b). The MF radar data is averaged over 1 day to remove the influence of tides. During the PMSE occurrence minimum period the MF radar indicates variable meridional wind with some occurrence of significant negative (poleward) values. The zonal wind showed a shear in the middle of the PMSE region around $85 \mathrm{~km}$ altitude throughout the period as is expected at the summer mesopause (Fig. 3a).
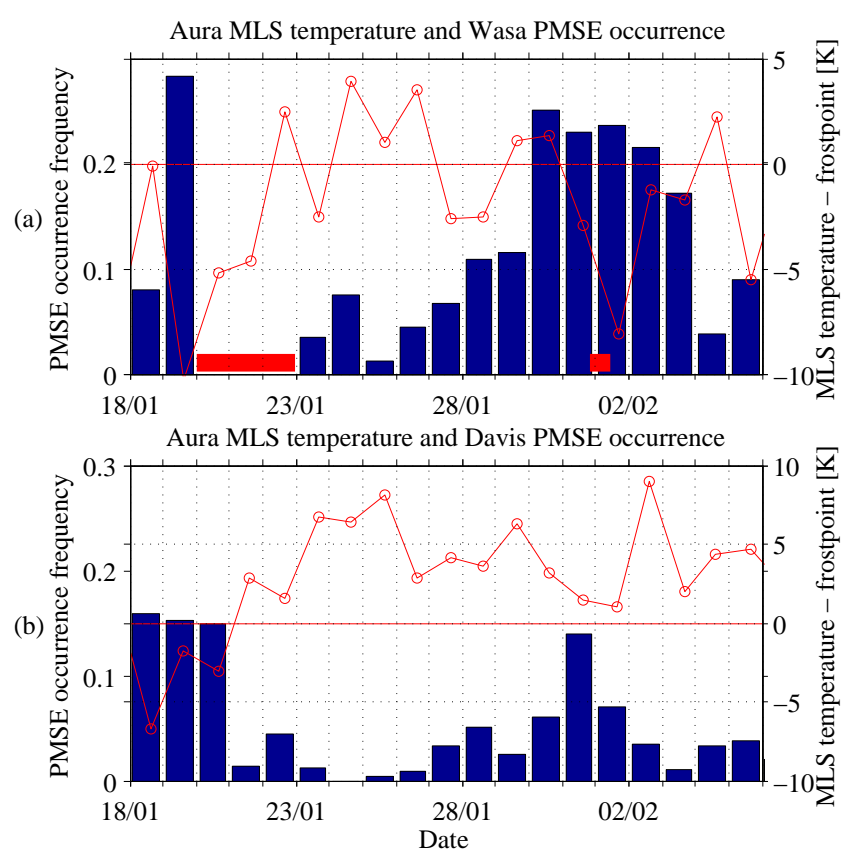

Fig. 1. Occurrence frequency of PMSE for each day for Wasa (top panel) and Davis (bottom panel), left y-axis. Data between 80 and $90 \mathrm{~km}$ were used. Periods when the MARA radar at Wasa was not operating are indicated by thick horizontal red lines. The temperature minus the frostpoint as estimated from Aura MLS measurements are shown with red lines, right y-axis.

\subsection{Altitude and diurnal distribution of PMSE}

The occurrence frequency and strength of PMSE above Wasa and Davis varied considerably during the measurement period. We have therefore opted to calculate average altitude and diurnal profiles of PMSE strength and occurrence for the entire period and for a more uniform background period. The background period excludes the strong PMSE events on 1820 January and 30 January. Data from the whole PMSE season at Davis indicates that the relatively stronger PMSE during 18 to 20 January is actually more typical for the entire season (not shown). The diurnal and altitude distributions of the PMSE echoes are summarized in Fig. 4. Magnetic midnight occurs at 03:23 local solar time (LST) at Davis and at 01:18 LST at Wasa and these are indicated by vertical bars in Fig. 4, panels (c) and (d), with black for Wasa and red for Davis, and were calculated using the NASA GSFC web service at http://modelweb.gsfc.nasa.gov/models/cgm/ cgm.html.

The occurrence of PMSE above our threshold is lower at Davis compared to Wasa for altitudes below $88 \mathrm{~km}$. For the background period (dashed lines) the shapes of the height distributions of occurrence frequency are similar for the two sites. The PMSE occurrence frequency is then higher at Wasa than at Davis for all altitudes. The altitude profile of echo strength (panel b) further emphasizes the similarity in the 

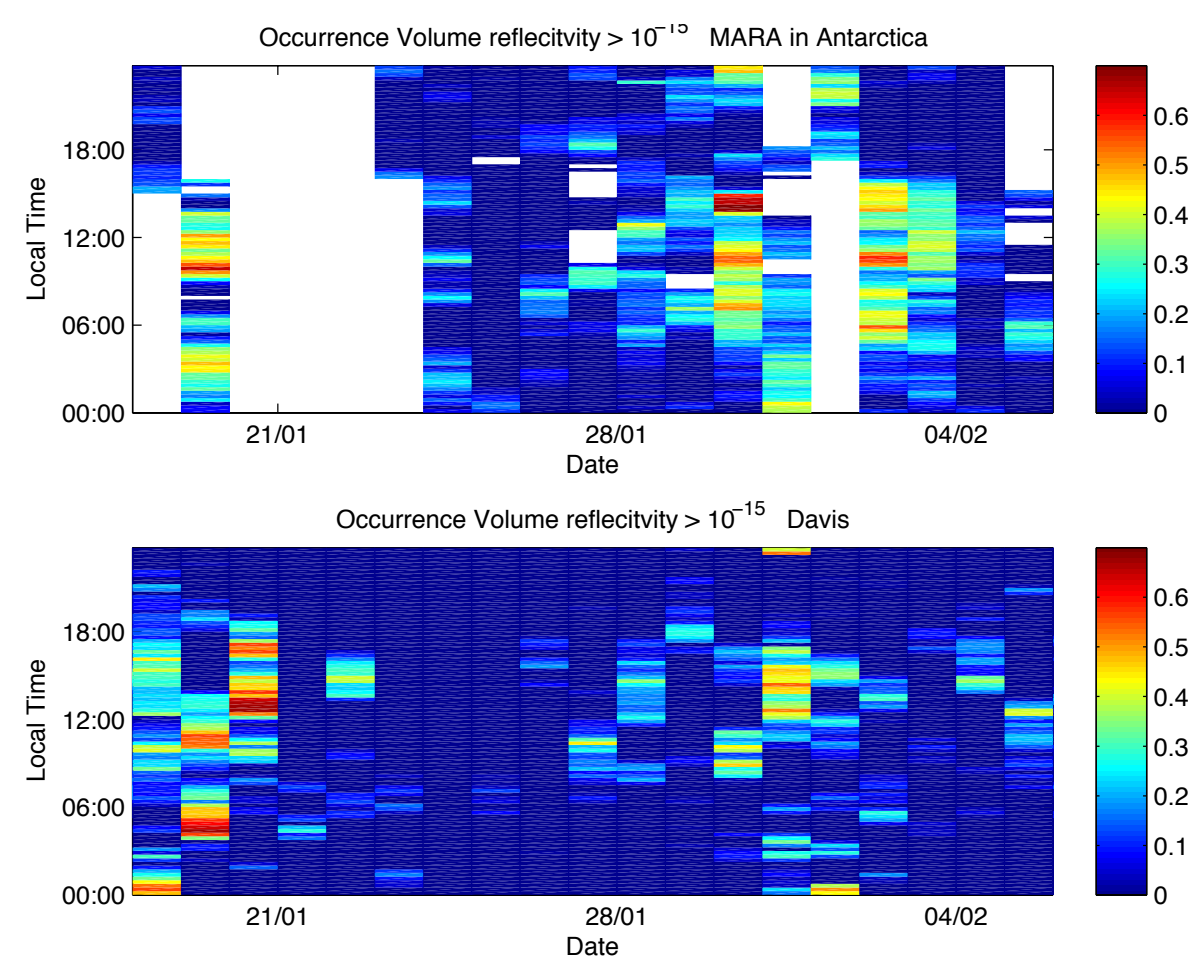

Fig. 2. Occurrence frequency of PMSE for each day for Wasa (top panel) and Davis (bottom panel). Data between 80 and $90 \mathrm{~km}$ were used. The $\mathrm{x}$-axis shows the Date and the $\mathrm{y}$-axis the local solar time.

echo profile for the background (dashed line) period. There is a significant difference in the shape of the profile only at the lowest altitude around $82 \mathrm{~km}$.

The diurnal distributions of the PMSE occurrence and average volume reflectivity are similar for Davis and Wasa. Both distributions show pronounced minima starting at about 15:00 to 16:00 LST. The decline in occurrence is steeper at Wasa. The minimum is more pronounced at Davis, with particularly low occurrence frequency between 18:00 and 22:00 LST. It is difficult to set a clear end for the minimum from the Wasa data but there is an increasing trend from about 21:00 LST. Day-to-day variability is large, and the onset of the evening minimum is the statistically most significant feature. The deepest part of the occurrence frequency minimum is reached at about the same magnetic local time for both sites, as is the end of the deepest minimum. The deepest part of the occurrence frequency minimum is between 15:00 and 19:00 MLT at both sites. Variability in occurrence frequency is also lower for the deepest minimum, making it clearly significant from a statistical point of view, despite the large day to day variability. We show this in Fig. 5 where we show the standard deviation of the occurrence frequency in the 82 to $88 \mathrm{~km}$ altitude interval for Wasa (black) and Davis (red). The plot is rather similar to the occurrence frequency plot. The most notable features are that the variance goes down at about the same local solar time at both sites, and increase rather suddenly at about the same mag- netic local time, just after 19:00 MLT. Vertical bars indicates 19:00 MLT for Wasa (black) and Davis (red).

We provide a plot of the diurnal variation of the average volume reflectivity in Fig. 4d. The average volume reflectivity varies by orders of magnitude and features in such a plot may come from individual days when only 16 days of data are available. This is the case for the peak around magnetic midnight at Davis.

\subsection{MLS estimates of temperature and frostpoint}

MLS data are retrieved for fixed pressure levels. These can then be gridded on geopotential height levels estimated from the MLS data. We have used data gridded on 81 , 84 and $87 \mathrm{~km}$ geopotential height. The geometric altitude is about $1.8 \mathrm{~km}$ higher, where $1.35 \mathrm{~km}$ is the typical difference between geopotential height and geometric altitude and $0.45 \mathrm{~km}$ is a suspected bias in the MLS data as reported in Schwartz et al. (2008). We have added $2 \mathrm{~km}$ (rounding off decimals) to the geopotential height in the rest of this document.Two altitude points from the MLS data were used to characterize the conditions at the mesopause: 83 and $86 \mathrm{~km}$. We have investigated the MLS data from $89 \mathrm{~km}$ as well. The error estimates for the temperature are less than $2 \mathrm{~K}$. The frost point error estimates are for $83 \mathrm{~km}$ about $5 \mathrm{~K}$, for $86 \mathrm{~km}$ about $15 \mathrm{~K}$ and for $89 \mathrm{~km}$ about $250 \mathrm{~K}$. These error estimates are systematic error estimates from the MLS data retrieval 
procedure, they do not represent the noise level in the data. The temperature estimate varies more than the frost point estimate in the time series. Despite this, and the large error estimates for the frost point, agreement between PMSE occurrence is better for the temperature minus frost point than for just temperature. We have chosen not to use the $89 \mathrm{~km}$ frost point value because of the enormous error estimate from the version 2.2 data processing software. One may further note that the absolute level of the MLS temperature minus frost point has changed considerably between MLS version 1.5 and version 2.2 processing software. Therefore one should mainly consider the relative variation in temperature minus frost point for this comparison. We present data using the latest public version of the MLS data, version 2.2. Because of the orbit of the Aura satellite and the way the MLS instrument is operated MLS data for the locations of Wasa and Davis were obtained for two local solar time ranges each day: around 15:00 to 16:00 LST and around midnight LST. We will only use the former data set. The temperature minus the frost point is shown as red lines in Fig. 1, using the right hand scale. Data for the location of Wasa is shown in panel (a) and for Davis in panel (b). A rather good general agreement can be found with higher occurrence frequency for lower temperature relative to the frost point. In Fig. 6 we show a scatter plot of the daily occurrence frequency as a function of the temperature minus frost point at 15:00 to 16:00 LST. Data for Wasa is shown with black circles and Davis data with red triangles. A trend can be seen, though the Wasa data shows some scatter. Least square fits of a linear function are shown with solid lines. A thick black line indicates a fit to all the data, with PMSE occurrence frequency $=0.08-0.012 \times\left(T-T_{\text {frost }}\right)$. The correlation coefficient is -0.7 and within the range -0.45 to -0.84 with $95 \%$ confidence. The likelihood that the real correlation is 0 is $10^{-5}$. The relationship between temperature and daily occurrence frequency is almost the same for the individual sites, the coefficient for the temperature dependence is within 0.001 of the value for the combined data set. MLS data shows that the temperature was typically further below the frost point before 18 January (not shown). The time interval of simultaneous measurements appears to represent a transition from the main PMSE season to an end of season interval when the average mesopause state is no longer favorable for PMSE formation.

The previous studies cited in the introduction have concerned a latitude dependence of the PMSE strength and occurrence frequency. Is it possible that the difference between the Wasa and Davis sites is due to a consistent longitude difference in the atmosphere, rather than due to the change of latitude? Wasa and Davis are almost $90^{\circ}$ apart in longitude. In order to assess this possibility we have compared the temperature difference between the Wasa site and a point at the same longitude as Davis but the same latitude as Wasa, and with a point at the same latitude as Wasa but the same longitude as Davis. We used Aura MLS data from the three
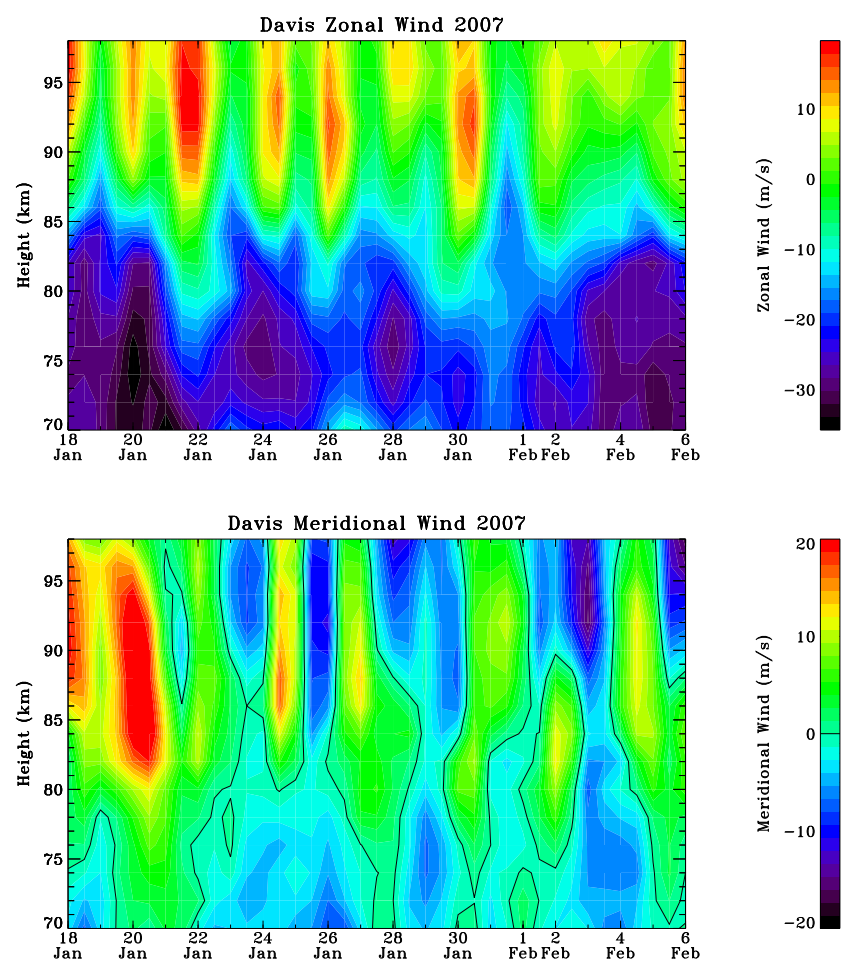

Fig. 3. Davis MF radar wind data, running average over 1 day. The top panel shows the zonal wind and the bottom panel the meridional wind $\left[\mathrm{m} \mathrm{s}^{-1}\right]$, as a function of date (x-axis) and height (y-axis).

pressure levels corresponding approximately to altitudes of 83,86 and $89 \mathrm{~km}$. The result is shown in Fig. 7. Temperature data was averaged over 5 degree latitude and 30 degree longitude around the sites of interest. As can be seen there is a consistent difference with latitude, on average $-4.4 \mathrm{~K}$ over the measurement period. This is about the same as the zonal average temperature difference between the two latitudes (not shown). There is also some difference with longitude, $+0.9 \mathrm{~K}$ over the measurement period. This means that the longitude of Wasa was somewhat warmer than the longitude of Davis for this period. Averaging over longer periods yields an average longitudinal difference close to zero as can be expected for traveling wave disturbances (not shown).

\section{Discussion}

\subsection{Day-to-day variation of PMSE}

The PMSE daily occurrence rates are, with our threshold of volume reflectivity above $10^{-15} \mathrm{~m}^{-1}$, typically higher at Wasa than at Davis (Fig. 1). Two clear maxima can be distinguished at both sites, one in the beginning (18-20 January for Davis) and one around 31 January. The first maximum corresponds to equatorward meridional winds and low mesospheric temperatures, well below the frost point (at 15:00 to $16: 00 \mathrm{LST}$ ). The mesospheric temperature relative to the 

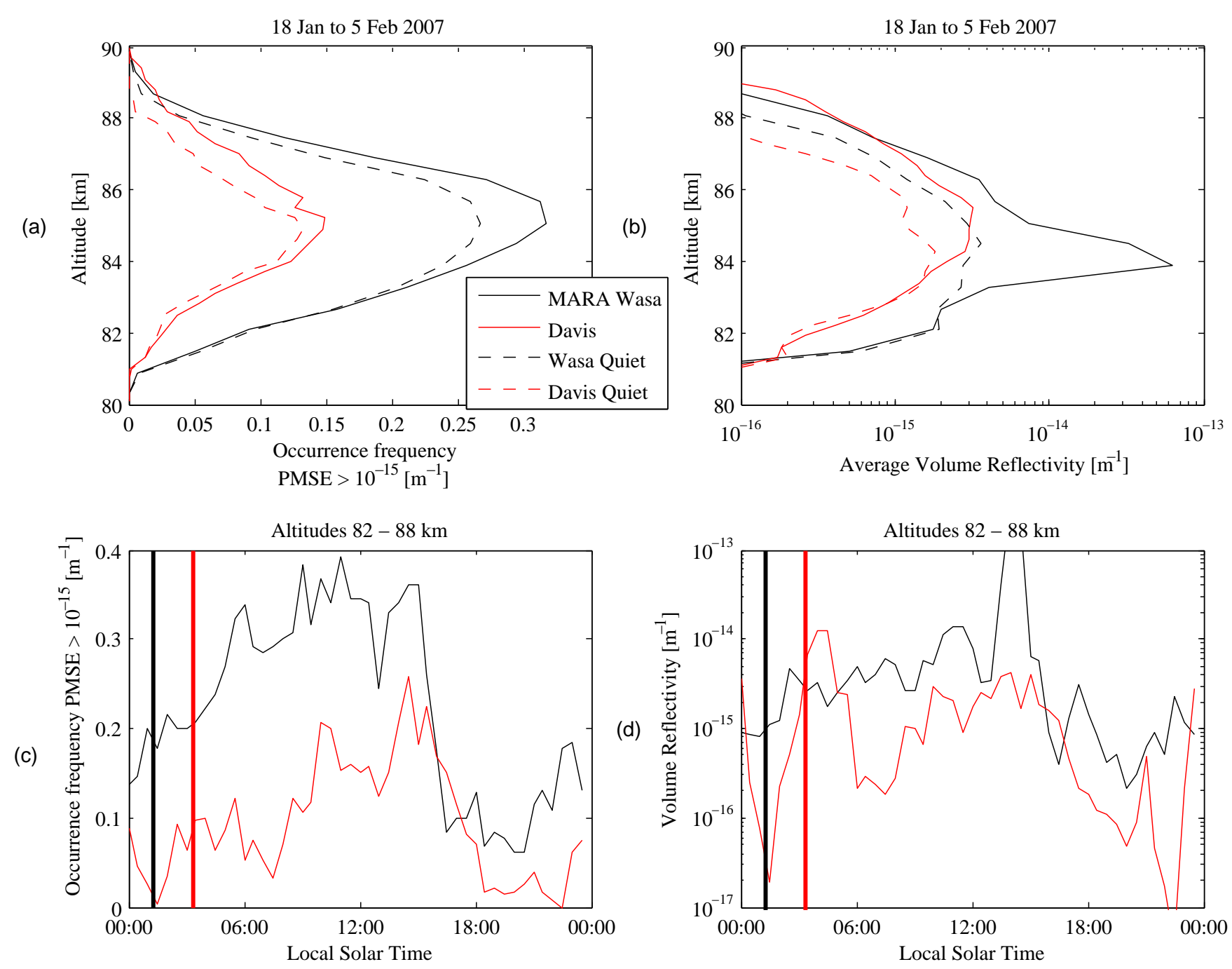

Fig. 4. The two upper panels show average altitude profiles of PMSE occurrence frequency (left) and PMSE volume reflectivity (right). The solid lines show the average for all days. Dashed lines show the average when days with unusually strong PMSE have been removed (see text for details). The two lower panels shows the average occurrence frequency (left) and the average volume reflectivity (right) in the altitude interval $82-88 \mathrm{~km}$ as a function of local solar time. Data from MARA Wasa are shown with a black line, data from Davis with a red line. Thick vertical bars indicate magnetic midnight at Wasa (black) and at Davis (red).

frost point then increases with a corresponding decrease in PMSE occurrence. During the second maximum in PMSE occurrence we once again see temperatures well below the frost point at Wasa in the 15:00 to 16:00 LST range. At Davis we see for the same time the lowest temperatures since the first maximum, but still above the frost point. Occurrence frequencies are also lower at Davis than at Wasa for this time. The general day-to-day variation follows what can be expected from the measured mesopause conditions regarding temperature and frost point. The relation between mesopause temperature below the frost point and daily PMSE occurrence frequency was found to be the same at the two sites.

Wasa and Davis are located at both different latitudes and different longitudes. Zonal mean temperatures observed with
MLS clearly decrease between the latitude of Davis and the latitude of Wasa. The temperature difference between the latitudes of Wasa and Davis for a restricted longitude interval around Wasa for our measurement period showed an average difference of $-4.4 \mathrm{~K}$ If there are standing waves or significant long period wave activity it is (at least in principle) possible to have a significant zonal difference between the two sites over our relatively short measurement period. MLS measurements showed that at the latitude of Wasa the mean temperature difference between the longitude of Wasa and the longitude of Davis was $+0.9 \mathrm{~K}$. This is smaller in magnitude than the difference due to different latitudes, but more important, the temperature was higher at the longitude of Wasa. Therefore the higher PMSE occurrence frequency 


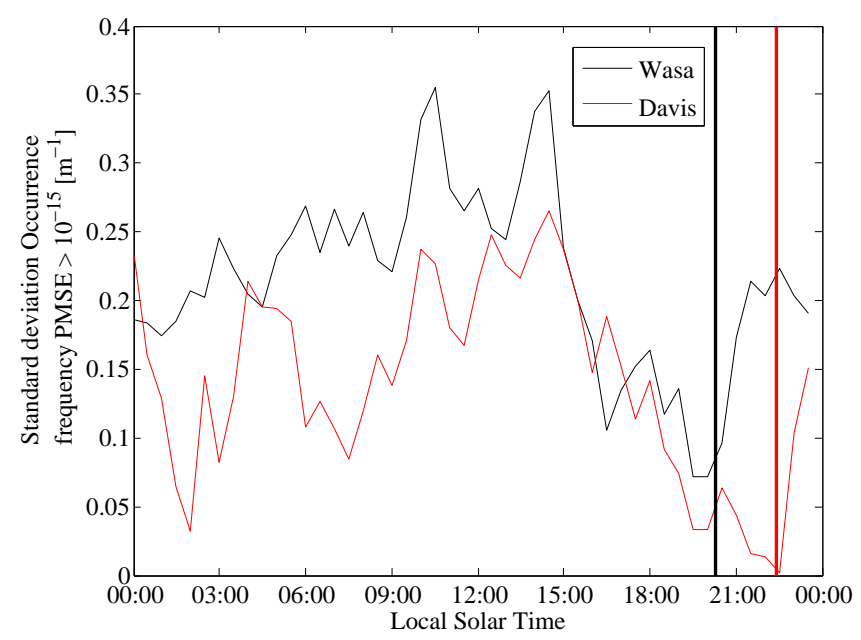

Fig. 5. The standard deviation of the occurrence frequency in the altitude interval $82-88 \mathrm{~km}$ as a function of local solar time. Data from MARA Wasa are shown with a black line, data from Davis with a red line. Thick vertical bars indicate 19 magnetic local time at Wasa (black) and at Davis (red).

at Wasa and associated temperature difference between Wasa and Davis cannot be attributed to the different longitudes of the two observation sites. It is clear that it is the difference in latitude which is the most important factor.

Our observations therefore support the latitude dependence of the LIMA/ice model presented by Lübken and Berger (2007) which shows that mean temperatures should be lower and PMSE should be more frequent at Wasa than at Davis. The difference should be greatest at the start and the end of the PMSE season. In Lübken and Berger (2007) their Fig. 7, we can see that for the start of our PMSE observations (i.e. 18 January) PMSE occurrence frequency in the LIMA/ice model was about $40 \%$ at the latitude of Davis and about $80 \%$ at the latitude of Wasa. We can therefore confirm that we indeed see differences between the two latitudes at the end of the PMSE season similar to those seen in the LIMA/ice model. The length of the season differs between the model and our observations. One reason for this can be a year to tear difference. However, just as for the Davis radar data discussed in Lübken and Berger (2007) the end of strong PMSE and relatively high PMSE occurrence frequency at Davis coincide fairly well with the end of the season from the LIMA/ice model (i.e. at about 20 January).

There is also a clear tendency towards strong equatorward winds during extended periods of increased PMSE occurrence, in accordance with previous findings (Morris et al., 2006, 2007). PMSE was typically associated with low temperatures as estimated from satellite data and equatorward meridional wind measured by MF radar. Also for winter conditions in 2002 Espy et al. (2003) have reported simultaneous abrupt shifts in the $\mathrm{OH}$ nightglow temperature estimates at Rothera $\left(67.6^{\circ} \mathrm{S}\right)$ and Halley $\left(75.6^{\circ} \mathrm{S}\right)$ which were associ-

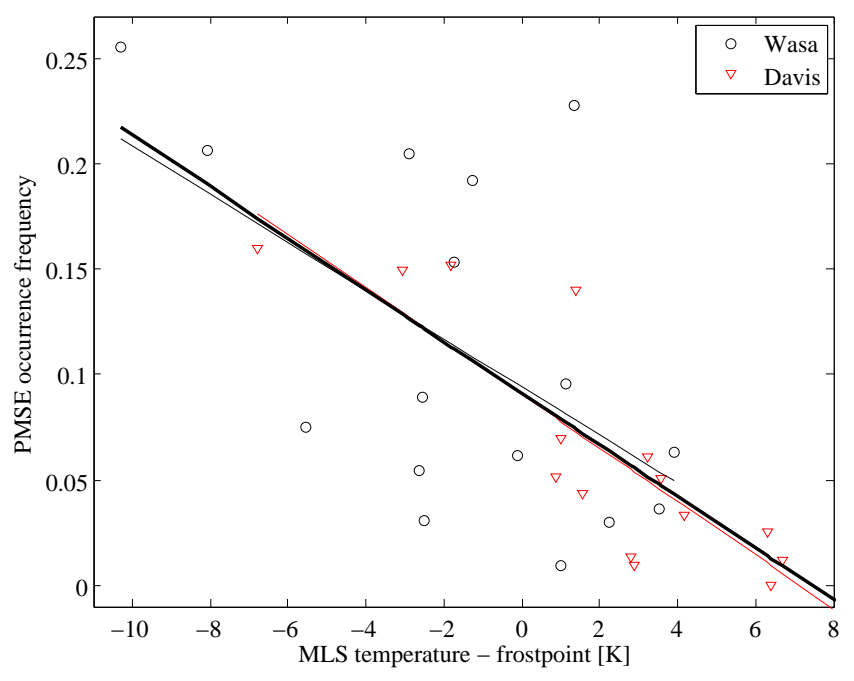

Fig. 6. Scatter plot of temperature minus frost point from Aura MLS data, average of data points centered on 83 and $86 \mathrm{~km}$ altitude (x-axis $[\mathrm{K}])$ and PMSE occurrence frequency (y-axis). Wasa data is shown with black circles, Davis with red triangles. Least square fits of a linear function are shown with solid lines. A thick black line indicates a fit to all the data.

ated with changes in the meridional flow as measured by the Rothera MF radar. Temperatures were lower for equatorward flow and the variations were interpreted as changes in the inter-hemispheric meridional jet and a corresponding modulation of the mesospheric descent and adiabatic heating rates over the polar region. The coincidence of PMSE minimum at both Davis and Wasa, increased temperature relative to the frost point, and reduced equatorward winds 22-27 January suggests an overall weakening of the mesospheric summer wind system during that time.

\subsection{Diurnal distribution of PMSE}

The broad midday maximum and evening minimum, typical for the diurnal distribution of PMSE, can clearly be distinguished for both sites. Inspection of Fig. 4c reveals that the occurrence frequency starts to fall at about 15:00 to $16: 00 \mathrm{LST}$ at both sites. The negative slope in occurrence frequency is steeper at Wasa than at Davis. The occurrence frequency starts to increase from the low evening values towards the midday maximum much earlier at Wasa and this is the main difference in the shape of the diurnal profiles. The deepest afternoon minimum is between 15:00 and 19:00 magnetic local time (MLT) at both sites. This feature was further confirmed by a study of the standard deviation (variability) of the diurnal PMSE occurrence frequency. The variability is lower in the minimum region, which is thus consistently low. The variability at both sites increased significantly just after 19:00 MLT. Wasa and Davis are situated on each side of the statistical auroral oval. Statistical 


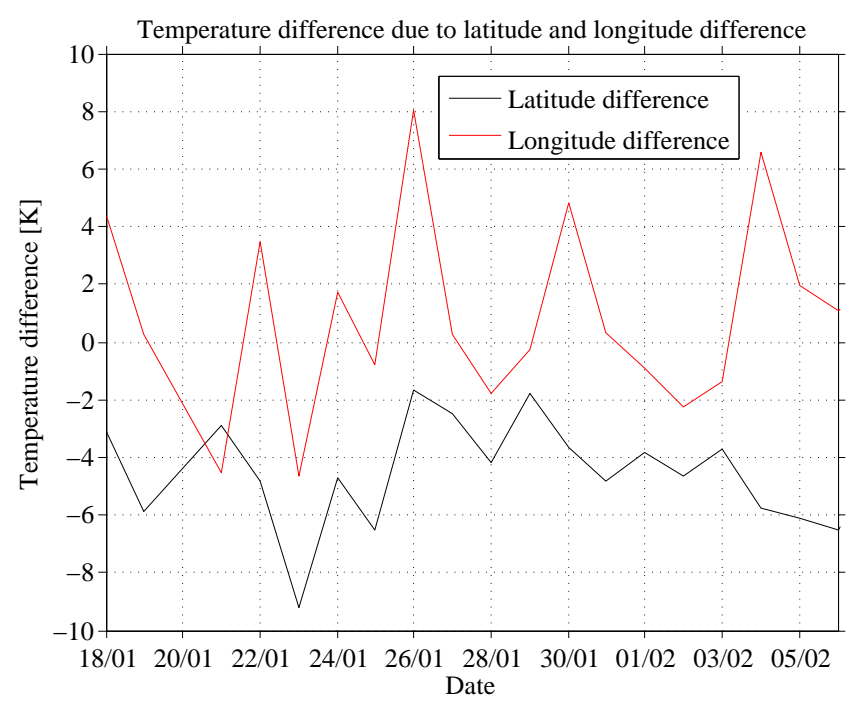

Fig. 7. Temperature difference between different sites due to latitude and longitude difference. The black curve shows the MLS observed mesopause temperature difference between the Wasa site and a a site at the same longitude as Wasa and the same latitude as Davis. The red line shows the temperature difference between Wasa and a site at the same latitude as Wasa and the same longitude as Davis. MLS temperature data from three pressure levels corresponding to approximate altitudes of 83 to $89 \mathrm{~km}$ were used.

maps of the latitudinal and magnetic local time distribution of medium energy $(30 \mathrm{keV}-2.5 \mathrm{MeV})$ charged particle precipitation likely to affect the mesopause region show that the precipitation can be expected to be very similar at the two sites (Codrescu et al., 1997), each site on different sides of the statistical maximum in electron precipitation. The magnetic local time dependence of the precipitation is the same, with a minimum in charged electron precipitation in the afternoon between about 14:00 to 19:00 MLT. This agrees fairly well with the time of the deepest minimum in our data. The occurrence frequency starts to fall earlier than that, and at different MLT but similar LST at the two sites. The daily variation is large and clearly more data is needed before we can determine if the charged particle precipitation plays a role in the evening minimum in PMSE occurrence. The fact that the variability is lower in the evening minimum period is however encouraging.

The similarity between the expected charged particle precipitation at Wasa and Davis, and the difference in PMSE occurrence and strength, further emphasize the importance of the geographic latitude-dependent temperature and water vapor for the PMSE occurrence in general. The high latitude station will also have a somewhat more favorable solar zenith angle for the time of minimum charged particle precipitation, so that the difference in the evening minimum can be related to availability of an ionization source.

\subsection{Altitude distribution of PMSE}

Removing days which were extreme for the period of study, the difference in altitude distribution between the two sites is smaller than the general variability. This can be compared with lidar observation results compiled by Chu et al. (2003). Their survey of Northern Hemisphere observations showed that the mean altitude of polar mesospheric clouds in the Northern Hemisphere varied very little depending on latitude (mean altitudes between 81.8 and $83.4 \mathrm{~km}$ were reported for sites from $54^{\circ} \mathrm{N}$ to the pole). Our observations also indicate that the average altitude of PMSE is not strongly latitude dependent, but more data would certainly be needed before any firm conclusions can be made.

\section{Conclusions}

We have found that PMSE over Antarctica for the period 18 January to 5 February 2007 were generally stronger at the higher geographic latitude station Wasa, than at the lower geographic latitude site Davis. It has previously been shown that PMSE at Davis were weaker and less frequent than at a similar geographic latitude site in the Northern Hemisphere, Andenes (Latteck et al., 2007). It has also been shown that PMSE at the end of the PMSE season at the high latitude Southern Hemisphere station Wasa were similar to end of the season PMSE at Kiruna which is at a lower latitude in the Northern Hemisphere (Kirkwood et al., 2007). Our results tie these findings together by showing with truly simultaneous measurements that we see more and stronger PMSE at the higher geographic latitude of Wasa than at Davis. We have also investigated the potential importance of the different longitude of the two radar sites by looking at Aura MLS temperature data. It was found that the longitude region around Wasa was on average $0.9 \mathrm{~K}$ warmer than the longitude region around Davis, so that longitude differences did not contribute to the higher PMSE occurrence at Wasa as compared to Davis.

Comparison with Aura MLS data of the temperature and the frost point indicated that the day-to-day variability in PMSE occurrence frequency, as well as the difference between the two Antarctic sites, can largely be explained by differences in the mesopause temperature and water vapor content. For the interval 15:00 to 16:00 LST the relation between daily PMSE occurrence frequency and temperature minus frost point was the same at the two sites. The main reason for the latitude variation is thus a change in temperature and water vapor content with latitude for the particular observation period reported here. The variation with latitude is in qualitative agreement with the latitude variation of the LIMA/ice model, in particular for the end season of the PMSE.

The diurnal distribution of PMSE seemed to be fairly similar at the two sites. Both showed a midday maximum, 
followed by a clear evening minimum in PMSE occurrence frequency. Occurrence frequencies remained low for a longer time at Davis after the onset of the evening minimum. The occurrence frequency started to fall at about the same LST towards the values in the deepest part of the evening PMSE occurrence frequency minimum. The deepest part of the minimum started and ended at the same MLT, 15:00 to 19:00 MLT. This in turn is in agreement with a minimum in energetic charged particle precipitation likely to affect the mesopause region. More data will be needed to discriminate between LST and MLT influences on the diurnal variation. It is however encouraging that the variability of the PMSE occurrence was low during the evening minimum and increased for both sites at the same MLT but at rather different LST.

The shapes of the altitude profiles for the conditions prevailing during the measurement period were rather similar. The shape differed at low altitudes, $82 \mathrm{~km}$ and below, with relatively more and stronger echoes at Wasa. For some more intense events, there was more PMSE at high altitude at Davis. The differences in the shapes of the altitude distributions were smaller than the general variability.

Acknowledgements. We thank Knut and Alice Wallenberg's foundation for funding MARA, Swedish Polar Research Secretariat and the Davis MST radar technical support crew for technical assistance. Aura MLS data used in this study was distributed by Goddard Earth Sciences Data and Information Services Center Distributed Active Archive Center.

Topical Editor U.-P. Hoppe thanks R. F. Woodman and another anonymous referee for their help in evaluating this paper.

\section{References}

Balsley, B. B., Woodman, R. F., Sarango, M., Urbina, J., Rodriguez, R., Ragaini, E., and Carey, J.: Southern hemisphere PMSE: Where are they?, Geophys. Res. Lett., 20, 1983-1985, 1993.

Chu, X., Gardner, C. S., and Roble, R. G.: Lidar studies of interannual, seasonal and diurnal variation of polar mesosperic clouds at the South Pole, J. Geophys. Res., 108, 8447, doi:10.1029/2002JD002524, 2003.

Codrescu, M. V., Fuller-Rowell, T. J., Roble, R. G., and Evans, D. S.: Medium energy particle precipitation influences on the mesosphere and lower thermosphere, J. Geophys Res., 102, 19977-19987, 1997.

Espy, P. J., Hibbins, R. E., Jones, G. O. L., Riggin, D. M., and Fritts, D. C.: Rapid, large-scale temperature changes in the polar mesosphere and their relationship to meridional flows, Geophys. Res. Lett., 30, 1240, doi:10.1029/2003GL016452, 2003.

Gage, K. S.: Radar observations of the free atmospher: Structure and dynamics, in: Radar in Meteorology, edited by Atlas, D., pp. 534-565, Am. Meteorol. Soc., Boston, 1990.

Huaman, M. M., Kelley, M. C., Hocking, W. K., and Woodman, R. F.: Polar mesosphere summer echo studies at $51.5 \mathrm{MHz}$ ar Resolute Bay, Canada: Comparison with Poker Flat results, Radio Sci., 36, 1823-1837, 2001.
Kirkwood, S. and Stebel, K.: Influence of planetary waves on noctilucent cloud occurrence over NW Europe, J. Geophys. Res., 108, 8440, doi:10.1029JD002356, 2003.

Kirkwood, S., Barabash, V., Brändström, B. U. E., Moström, A., Stebel, K., Mitchell, N., and Hocking, W.: Noctilucent clouds, PMSE and 5-day planetary waves: a case study, Geophys. Res. Lett., 29, 1411, doi:10.1029/2001GL014022, 2002.

Kirkwood, S., Wolf, I., Nilsson, H., Dalin, P., Mikhaylova, D., and Belova, E.: Polar mesosphere summer echoes at Wasa, Antarctica $\left(73^{\circ} \mathrm{S}\right)$ : First observations and comparison with $68^{\circ} \mathrm{N}$, Geophys. Res. Lett., 34, L15803, doi:10.1029/2007GL030516, 2007.

Lambert, A., Read, W. G., Livesey, N. J., Santee, M. L., Manney, G. L., Froidevaux, L., Wu, D. L., Schwartz, M. J., Pumphrey, H. C., Jimenez, C., Nedoluha, G. E., Cofield, R. E., Cuddy, D. T., Daffer, W. H., J.Drouin, B., Fuller, R. A., Jarnot, R. F., Knosp, B. W., Pickett, H. M., Perun, V. S., Snyder, W. V., Stek, P. C., Thurstans, R. P., Wagner, P. A., Waters, J. W., Jucks, K. W., Toon, G. C., Stachnik, R. A., Bernath, P. F., Boone, C. D., Walker, K. A., Urban, J., Murtagh, D., Elkins, J. W., and Atlas, E.: Validation of the Aura Microwave Limb Sounder middle atmosphere water vapor and nitrous oxide measurements, J. Geophys. Res., 112, D24S36, doi:10.1029/2007JD008724, 2007.

Latteck, R., Singer, W., Morris, R. J., Holdsworth, D. A., and Murphy, D. J.: Observations of polar mesosphere summer echoes with calibrated VHF radars at $69^{\circ}$ in the Northern and Southern hemispheres, Geophys. Res. Lett., 34, L14805, doi:10.1029/2007GL030032, 2007.

Latteck, R., Singer, W., Morris, R. J., Hocking, W. K., Murphy, D. J., Holdsworth, D. A., and Swarnalingam, N.: Similarities and differences of Polar Mesosphere Summer Echoes observed in the Arctic and Antarctica, Ann. Geophys., 26, 2795-2806, 2008, http://www.ann-geophys.net/26/2795/2008/.

Lübken, F. J. and Berger, U.: Interhemispheric comparison of mesospheric ice layers from the LIMA model, J. Atm. Sol. Terr. Phys., 69, 2292-2308, doi:10.1016/j.jastp.2007.07.006, 2007.

Lübken, F. J., Müllemann, A., and Jarvis, M.: Temperatures and horizontal winds in the Antarctic summer mesosphere, J. Geophys Res., 109, D24112, doi:10.1029/2004JD005133, 2004a.

Lübken, F. J., Zecha, M., Höffner, J., and Röttger, J.: Temperatures, polar mesosphere summer echoes, and noctilucent clouds over Spitsbergen (78 ${ }^{\circ}$, J. Geophys Res., 109, D11203, doi:10.1029/2003JD004247, 2004b.

Morris, J., Klekociuk, A. R., Latteck, R., Singer, W., Holdsworth, D. A., and Murphy, D. J.: Inter-hemispheric asymmetry in polar mesosphere summer echoes and temperature at $69^{\circ}$ latitude, J. Atmos. Solar Terr. Phys., published online, doi:10.1016/j.jastp.2008.09.042, 2008.

Morris, R. J., Murphy, D. J., Vincent, R. A., Holdsworth, D. A., Klekociuk, A. R., and Reid, I. M.: Characteristics of the wind, temperature and PMSE field above Davis, Antarctica, J. Atmos. Solar Terr. Phys., 68, 418-435, 2006.

Morris, R. J., Murphy, D. J., Klekociuk, A. R., and Holdsworth, D. A.: First complete season of PMSE observations above Davis, Antarctica, and their relation to winds and temperatures, Geophys. Res. Lett., 34, L05805, doi:10.1029/2006GL028641, 2007.

Murphy, D. J., French, W. J. R., and Vincent, R. A.: Longperiod planetary waves in the mesosphere and lower thermosphere above Davis, Antarctica, J. Atmos. Solar Terr. Phys., 69, 2118-2138, 2007. 
Rapp, M. and Lübken, F.-J.: Polar mesosphere summer echoes (PMSE): Review of observations and current understanding, Atmos. Chem. Phys., 4, 2601-2633, 2004, http://www.atmos-chem-phys.net/4/2601/2004/.

Schwartz, M. J., Lambert, A., Read, G. L. M. W. G., Livesey, N. J., Froidevaux, L., Ao, C. O., Bernath, P. F., Boone, C. D., Cofield, R. E., Daffer, W. H., J.Drouin, B., Fetzer, E. J., Fuller, R. A., Jarnot, R. F., Jiang, J. H., Knosp, B. W., Krüger, K., Li, J.-L. F., Mlybcak, M. G., Pawson, S., III, J. M. R., Santee, M. L., Snyder, W. V., Stek, P. C., Thurstans, R. P., Tompkins, A. M., Wagner, P. A., Walker, K. A., Waters, J. W., and Wu, D. L.: Validation of the Aura Microwave Limb Sounder Temperature and Geopotential Height Measurements, J. Geophys. Res., 113, D15511, doi:10.1029/2007JD008783, 2008.
Woodman, R. F., Balsley, B. B., Aquino, F., Flores, L., Vazquez, E., Sarango, M., Huaman, M., and Soldi, H.: First observations of polar mesosphere summer echoes in Antarctica, J. Geophys Res., 104, 22 577-22 590, 1999. 